\title{
Por que a narrativa? Uma reflexão sobre a filosofia da história hegeliana
}

\author{
URIEL MASSALVES DE SOUZA DO NASCIMENTO *
}

* Doutorando em filosofia (PUC-RIO)

Bolsista CNPq
RESUMO A obra hegeliana Lições sobre filosofia da história talvez seja aquela sobre a qual menos comentadores de língua portuguesa se debruçam. O texto, contém uma peculiaridade que, mesmo quando explorada, o é de maneira parcial: seu caráter narrativo. Ao fim e ao cabo, ser uma narrativa parece algo supérfluo ou, no melhor dos casos, algo inerente ao objeto história, pouco sendo dito acerca do fato de ser a metodologia utilizada por Hegel em sua Fenomenologia e em toda obra posterior, ou seja, no método mesmo de exposição do Sistema. Pouco é dito, portanto, sobre o porquê da adequação entre forma e conteúdo e, mesmo quando o é, a ênfase é quase que exclusivamente colocada no conteúdo da narrativa e não tanto da imbricação entre método expositivo e método dialético. Tendo isso em vista, buscaremos argumentar que é impossível compreender o que significa a totalidade hegeliana quando se trata da história se ignorarmos o quão bem a metodologia narrativa serve como caminho expositivo à dialética, especialmente se pensarmos que esta tem por finalidade um Todo que se dá processualmente. Dito de outro modo, nosso ponto de vista será aquele que compreende é necessário, para que se possa entender a filosofia da história hegeliana, analisar a metodologia textual por ele utilizada. Com isso, extrair consequências da sua "forma textual” é fundamental para que se possa compreender o "conteúdo" desse mesmo texto. As aspas precedentes sinalizam uma suspensão inerente à própria formulação: se só pela forma podemos compreender o conteúdo, temos que a separação aristotélica, no referido texto, inexiste. Assim sendo, indicaremos de que maneira a narrativa serve como método de exposição precisamente porque abarca perfeitamente o método de compreensão e estruturação do real, a saber, a dialética e a racionalidade.

PALAVRAS-ChaVe Hegel; Filosofia da história; ontologia. 


\section{A NARRATIVA DO ESPÍRITO}

Não é incomum que se compare a Fenomenologia do Espírito e mesmo as Lições a um romance de formação (Bildungsroman), indicando aí o caráter edificador e construtor inerente à obra. A partir disso, faz-se a indicação de que a obra hegeliana teria uma dimensão profundamente similar ao Wilhelm Meister de Goethe, posto que tanto quanto no romance goethiano, o leitor e o personagem principal partiriam juntos da situação de ignorância e ingenuidade em direção ao esclarecimento através de sucessivas experiências. Leitor e personagem estariam ligados, uma vez que ler a experiência de um personagem seria experenciar em alguma medida aquilo que ele viveu. Arte e vida estariam imbricados em um mesmo movimento, posto que ler e viver estariam ambos subscritos à categoria modificadora da experiência, o que em alemão (Erfahrung), indica pôr-se em risco de aniquilação e, apesar disso, ir até o fim. Lida metaforicamente, a aniquilação de que falamos pode ser vista como uma espécie de morte da configuração do indivíduo tal e qual ela se dá antes da leitura para o surgimento de outra configuração existencial e, no caso de Hegel, também lógica e epistemológica. Pôr-se em risco e mesmo assim cumprir o caminho até o fim é, necessariamente, transformar-se.

A comparação com o romance de formação, no entanto, só pode nos levar até aqui. Não existe, nele, nada que garanta a consistência necessária a uma figura como o Espírito nem nada que garanta, nessa forma romanesca, a consistência necessária às circunvoluções da consciência que precisa apreender, de dentro de si mesma, as contradições do seu confronto com o objeto. Ademais, falta ao referido gênero o caráter duplo do para-nós/consciência, ou seja, falta ao romance a sabedoria de antemão da existência da conquista de um plateau mais elevado. O discurso hegeliano, ao fim e ao cabo, se dá em dois registros em quaisquer de suas obras: o daquele que caminha em conjunto com o leitor, como que experimentando com ele as dificuldades inerentes ao método dialético; e aquele que já sabe porque já chegou ao destino.

Ora, se a pergunta que nomeia nosso texto parece, de antemão, situar como garantido o direito à narrativa em Hegel, é exatamente porque não confundimos, como fazem 
alguns comentadores, narrativa com romance. A narrativa consegue se adequar à dialética e, num certo sentido, é ela mesma dialética, precisamente porque é um método de inscrição textual dos eventos numa ordem de imbricações necessárias. Dito de outro modo, a narrativa é adotada por Hegel em sua filosofia da história - ressaltemos que isso abrange todas as obras menos a Lógica e parte da Enciclopédia-precisamente porque é a forma textual pela qual a dialética pode se mostrar como motor da história.

Isso se deve, em parte, ao conceito de verdade presente na obra. Se lemos no parágrafo 20 da Fenomenologia que "o verdadeiro é o todo", lemos também que o todo é “a essência que se implementa através de seu desenvolvimento", o que significa que a totalidade não está dada de antemão (como um fundo), mas passa a existir com o tempo. Para a consciência, como para tudo o que se pode dizer de verdadeiro, o verdadeiro é aquilo que se totaliza no tempo, sendo comum que a totalização de uma figura não indique término, mas desdobramento no oposto ao qual se chega. É isso que se chama método dialético. Exemplificando o referido método com os três primeiros termos da Lógica hegeliana e aproveitando, com isso, para desfazer o engano de leitura que vê na dialética do autor “tese, antítese e síntese”, podemos dizer, de maneira um pouco resumida, o seguinte: o primeiro termo, Ser, é pura indeterminação e disso decorre que de dentro do Ser há o Nada. Ele surge, assim, como uma contradição inerente à própria figura do ser, uma vez que o Ser não possui, “no princípio”, qualquer determinidade. Dessa contradição entre as duas figuras, entretanto, surgirá uma terceira, que abarcará as duas mas as dissolverá no processo (é o que se chama de aufhebung). Essa figura é a do vir-a-ser que é a mesmo tempo Ser - posto que é - e nada, posto que também não é. Note-se que, com isso, perdemos ambos os termos em sua "pureza", mas mantivemos uma certa oposição, retirando-a, no entanto, do regime de contradição interna. Opostos unidos e ainda contraditórios entre si difere de síntese, pois que essa pressupõe um todo coerente, um pouco como $\mathrm{CO} 2$ responde de maneira diferente de simplesmente $\mathrm{C}$ e $\mathrm{O} 2$ separados.

Tendo em vista o que expusemos aqui acerca do método dialético, para elaborar sua história e sua filosofia da história seria preciso uma forma de escrita que fosse capaz de expor o Todo sob essa égide, de uma maneira tal que a consciência leitora caminhasse pari passu à exposição, estando existencialmente inscrita no processo de co-

$1 \quad$ HEGEL, 1992, p.31 
nhecimento. Pari passu indica bem que não é apenas a consciência que caminha com o conteúdo, mas o conteúdo, também ele, caminha. A consciência, agora já Razão, precisa apreender a realidade de maneira dialética, porque a dialética é, ela mesma, a estrutura do real e por isso, a maneira de a Razão conhecer os objetos.

A obviedade do fato de que na narrativa o conteúdo caminha com a leitura tanto quanto e em conjunto com o leitor, é diminuída quando consideramos que pensar uma totalidade nesses termos é o mesmo que conceber uma totalidade aberta e que se constrói, sendo bastante diferente de uma noção de totalidade sempre atual de Spinoza (ou, por outro caminho, Leibniz), de quem Hegel foi leitor. É uma noção de Todo que só se dá ao fim do ato de rememorar, o que faz com que Eagleton afirme que "a dimensão constativa de seu discurso (de Hegel) é inseparável de seu aspecto performativo"

Isso gera a imbricação já célebre entre a filosofia da história e a própria história, o que faz de Razão na história uma aberração ainda maior: separar o “conteúdo filosófico" da "história" é o mesmo que fazer uma leitura kantiana de Hegel, ou seja, não compreendê-lo. Não existe, aqui, uma separação entre o objeto “em si” (algo como “a história”) e uma filosofia que discorre sobre esse objeto (a “filosofia da história”): há, ao contrário, uma impossibilidade de separação e distinção da filosofia de seu objeto por conta da racionalidade intrínseca ao próprio objeto sobre o qual ela discorre. Não há, nesse sentido, nada que não seja racional, de modo que "tudo que é racional é real e tudo que é real é racional" 3 e a maneira pela qual essa racionalidade se mostra é a efetividade dos eventos históricos. Separar o “conteúdo filosófico” dos eventos é não compreender o motivo pelo qual já existe uma Lógica separada das Lições: lá é onde se deve buscar a estrutura do real sem quaisquer efetividades históricas, pois que lá se trata do que o próprio Hegel chamou de ciência pura. Aqui se trata da manifestação dessa ciência no efetivo.

Uma vez que a própria história também obedece à mesma dialética da Razão, é impossível, desde o ponto de vista da última, compreender o Espírito sem compreender sua história e suas relações, de modo que a rememoração serve não apenas como forma

3 HEGEL, 2017, s/p. 
de conhecer o passado, mas a maneira pela qual esse passado continua atuando no presente e constituindo aquilo que se compreende. Afinal, como Hegel salienta ao fim de sua exposição: “a vida desse espírito atual é um círculo de estágios que, vistos por um lado, existem simultaneamente e, por outro, aparecem como já passados. Os estágios que o espírito parece ter já ultrapassado, ele ainda possui em sua profundidade atual.”4

Ora, é o exato mesmo problema que se enfrenta quando se fala de uma narrativa. Considerada como um texto, a narrativa é precisamente aquela forma que jamais pode ser desmembrada, sendo sempre uma totalidade que não pode ser rompida posto suas partes serem organicamente ligadas. Sua organicidade, entretanto, inexiste até o momento de sua escrita: é a obra que cria, retroativamente, a necessidade dos capítulos e não só os capítulos que constroem a totalidade da obra. A narrativa pode ser lida, também ela, como uma rememoração da história contada. Pouco importa, aqui, se o escritor a concebe das partes ao Todo ou do Todo às partes: é apenas enquanto Todo que ela poderá fazer algum sentido enquanto narrativa e é só aí, nessa totalidade, que suas subdivisões farão sentido como caminhos dentro de ou em direção a algo. As ações, dentro da narrativa, ocorrem por uma lógica intrínseca à história narrada, onde história aqui pode significar tanto a história formal enquanto disciplina acadêmica quanto a história fictícia das narrativas.

É justo percebendo essa impossibilidade da imparcialidade que faz Hegel adotar o Espírito como “narrador” da história. Conforme Safatle observa, “para Hegel, quem narra a história não são os homens, mas o Espírito (...) no momento em que o Espírito sobe à cena e narra a história, sua prosa é radicalmente distinta da prosa dos indivíduos que testemunham fatos" ${ }^{5}$. Sua visão é omniabrangente e sua seleção de eventos é distinta daquela de um poeta grego ou de um historiador da época de Hegel. Isso porque o Espírito enquanto narrador não é coincidente nem com os homens narrando nem com os mesmos homens agindo, posto que, como a narrativa do Espírito mostra, a História sempre se passa às costas dos homens, pois “a relação [entre a substancia universal e a consciência subjetiva] se dá de tal modo que as ações dos humanos na história mundial produzem um efeito de todo diferente daquilo que eles intencionam

4 HEGEL, 1999, p.72.

5 SAFATLE, 2015 , p.175. 
e conseguem, daquilo que eles querem e sabem"6. As ações do homem são momentos que apenas farão sentido dentro da grande composição da história do Espírito.

A famosa frase segundo a qual na História "nada de grandioso foi feito sem paixão" só é compreensível se colocada ao lado de outra, segundo a qual a "paixão é o lado subjetivo, formal, da energia, da vontade e da atividade, no qual o conteúdo ou o objetivo ainda permanecem indeterminados"7. O que se torna evidente, aí, é que a história do Espírito (ou do mundo, Weltgeschichte) em Hegel não é uma força que é movimentada conscientemente pelos homens ou mesmo por algum grande agente, i.e. não é possível pensar a história hegeliana nem como a história dos homens que conscientemente a fazem, nem como se o Espírito fosse um ser voluntarioso que faz sua história como bem quer. Não há um “Espírito agente” em Hegel, mas um Espírito que caminha quase à força, aprendendo com o curso do mundo mais do que o guian$\mathrm{do}^{8}$. Dito de outro modo, o Espírito caminha sem, no entanto, interferir diretamente na caminhada que faz. Isso vai de encontro com algumas leituras de Hegel que atribuem ao autor certo fatalismo ou certa teleologia forte, no sentido mesmo de tudo estar previamente determinado. Num certo sentido, o que ocorre aqui é uma projeção do Deus de Leibniz 9 - que a tudo conhece e já escolheu o melhor mundo possível - no Espírito hegeliano. Nos acontecimentos históricos não existem quaisquer necessidades a priori que guiam o curso da história. É a narrativa hegeliana que retroativamente atribui necessidade lá mesmo onde apenas a contingência habitava.

Ademais, se podemos considerar a composição da história como sendo um ato, podemos dizer que ela é algo diferente dos fatos que ocorreram e dizer, também, que é algo que neles influi, na medida em que atua no presente que é por eles composto. Juntar as duas coisas - o ato de composição da história e a ocorrência dos próprios

6 HEGEL, 1999, p.94.

7 HEGEL, 1999, p.29

8 LEBRUN, 1988, p.22.

9 Nada aparentado a Leibniz, a necessidade de algo ocorrer, em Hegel, se mostra apenas no texto, ou seja, apenas quando o filósofo reflete sobre a história, a rememora e, num certo sentido, a constrói. É o fato de ter ocorrido que mostra que algo era necessário: até aí, Leibniz e Hegel concordariam. A diferença é que, diferente do que ocorre para Leibniz, não havia nenhum sujeito que possuía o saber prévio ou antevisão sobre aquele acontecimento. O Espírito de Hegel se desenvolve e se reconhece com os homens e, portanto, não pode ser o Deus de Leibniz, em si mesmo perfeito, conhecedor e agente que escolhe o melhor dos mundos. 
eventos - com base na premissa de que o Real é racional é o mesmo que supor existir uma necessidade anterior ou contemporânea ao evento, o que tornaria o momento de compor a narrativa histórica apenas um momento de rememorar no sentido mais simplório: contar algo que já foi tal como foi no momento de sua ocorrência. Como Zizek aponta, tal postura "confunde ser com devir; ela percebe como uma ordem fixa do Ser o que, para Hegel, é o processo do Devir, que engendra retroativamente sua necessidade”. É, portanto, apenas, retroativamente, ou seja, enquanto rememora, que as coisas "precisam ser dessa forma” e não antes do ato de rememoração, daí o motivo de ser, também ele (o ato rememorativo) uma intervenção na realidade. A necessidade da cadeia de eventos composta por Hegel torna-se, ao mesmo tempo, produto da contingência e do ato de construção da narrativa, sendo de ambos dependente. É a construção racional da narrativa que torna os eventos necessários, posto a época de sua ocorrência estarem eles passíveis de ser completamente diferentes. A “astúcia da razão”, temática comum nos estudos da filosofia da história hegeliana, é precisamente essa possibilidade do mover-se do Espírito apesar de e durante as contingências, instaurando nessa contingência uma vez ocorrida a necessidade. Dito de maneira clara: tudo é contingencial e possibilidade, até a sua ocorrência. A efetivação é o critério de uma necessidade que só será vista como tal a posteriori. Na história isso só se mostra claro efetivamente para os homens quando calha de ocorrer na figura de repetição: duas deposições para Napoleão e para os Bourbons mostram como aquilo que parecia uma contingência é necessário ${ }^{10}$ tanto quanto a escrita hegeliana da narrativa do Espírito repete os atos uma segunda vez, dessa vez em texto. Narrar é, também, um ato de rememoração, como já ressaltamos.

Se parece, num primeiro momento, que a identidade entre Ser e Pensamento enunciada logo ao começo ${ }^{11}$ invalida o que foi exposto aqui - ou seja, que os eventos históricos adquirem uma necessidade apenas retroativamente - é que esquece-se de um detalhe: o Pensamento vem sempre depois do fato de modo que, se quisermos ser fiéis à pena de Hegel, temos de levar a sério a imagem da filosofia como um pássaro de Minerva que levanta voo ao crepúsculo. Teríamos, ainda que apenas para fins de compreensão, que conceber toda a história da filosofia até ele como culminando em

10 HEGEL, 1999, p.266.

11 I.e. “o racional é real e o real é racional.” 
seu Sistema, uma vez que ele é o autor que as conserva e as abole a partir de uma rememoração, introduzindo a necessidade delas a posteriori ${ }^{12}$. Rauch, nesse sentido, compreende bem o ponto de uma história da filosofia hegeliana ao afirmar que "a razão manifesta si mesma no mundo e se realiza (is realized) nos dois sentidos da palavra: a razão se torna real ao preencher seu próprio padrão de racionalidade e a razão é apreendida (grasped) por ela mesma"13.

Por fim e para recapitular, se quiséssemos dar uma resposta mais direta à pergunta por nós mesmo colocada - por que a narrativa? - poderíamos listar ao menos quatro necessidades que a narrativa preenche: obediência ao método dialético ao inscrever as três dimensões temporais na escrita; ordenação em cadeias causais de eventos contingentes; desenvolvimento processual gradual do conteúdo rumo à totalidade; pedagogia do conceito à consciência leitora, que vê a história se desdobrar. Feito isso, entretanto, teríamos de deixar claro que é apenas de dentro do texto hegeliano que esses quatro fatores podem operar, uma vez que é somente a partir de sua leitura e do embate com o texto que o que chamamos de necessidade funciona. Isso se deve à natureza do texto hegeliano e é a dificuldade inerente a todo comentário sobre ele: comentar Hegel é, de antemão, saber-se alijado do próprio processo que comentar se propõe a ser - posto Hegel situar a experiência com o texto e o pensamento como centrais à filosofia. E, como a toda tarefa impossível, é uma tarefa à qual só se pode responder com a última frase d’O inominável, de Beckett: "I can't go on/I'll go on."14.

Esse ir adiante apesar de tudo, entretanto, não é uma teimosia ou um capricho, mas a condição mesma do comentário e, aventamos, da filosofia. Apesar de praticar comentários criativos que são exógenos à própria letra da obra - privilegiando, com trocadilho ou não, “o espírito” da obra - Hegel não foi aquele quem inaugurou a prática de comentários criativos: basta lembrarmos o que já fazia Platão com Sócrates, Górgias e Parmênides. Podemos, no entanto, dizer que Hegel foi o primeiro a utilizar-se de uma forma de reflexão que conjura filosofia e história numa narrativa na qual as duas disciplinas se interconectam de maneira indissociável. O que Hegel fez, com isso,

12 Pode-se ver aí tanto uma arrogância quanto uma humildade, mas pouco importa o julgamento da pessoa Hegel quanto o que temos em questão é sua filosofia e, quanto a isso, é coerente que na narrativa que construa seja ele a culminância da filosofia.

13 RAUCH, 1988b. P X (dez em romanos).

14 “Eu não posso seguir adiante/eu vou seguir adiante”. BECKETT, 2010, p.740. 
foi: a) conjugar todas as filosofias; e b) os comentários que fazia às filosofias que não eram as suas; numa grande narrativa que culmina nele enquanto último filósofo. Fez, portanto, um procedimento análogo ao procedimento antropofágico e, em seu movimento de realização gerou a identidade de sua filosofia. Dito de maneira mais direta, Hegel foi mais um dos grandes filósofos que fez do comentário o caminho para a sua filosofia, fazendo com que uma indistinção entre as duas coisas fosse notável. Tudo isso realizado ao mesmo tempo em que construía uma certa história do espírito. Afinal, não se pode ler sua História da filosofia sem se notar que cada autor comparece ali em sua verdade ao mesmo tempo em que sua filosofia é alterada ever so slightly para compor o desfile da Verdade do texto hegeliano.

Esse procedimento, o de tudo transformar em seu de modo que "nada de filosófico lhe seja estranho", é precisamente o que nos permite comentar um texto hegeliano sem incorrer num problema de filiação. Comentar Hegel, dadas as afirmativas que fizemos aqui, soaria como um erro: existiria apenas o sistema e o comentário seria, todo caso, supérfluo. Mas, se Hegel for de fato bem entendido, cabe para seu texto uma paráfrase jocosa da frase de Lacan ao comentar os textos de Freud: se o texto de Freud é o mais "perpetuamente aberto à revisão"15, como dizia Lacan em seu primeiro seminário, o pensamento de Hegel é exatamente aquele que nos ensina que "só existe revisão" ou seja, comentários criativos. Com ele(s) aprendemos que a novidade é sempre fruto de determinidades outras que nós mesmos. Logo, quer estejamos conscientes, quer não, nos fincamos com os dois pés numa tradição e num passado, sendo a novidade apenas um processo de composição diferenciado dessa mesma tradição e desse mesmo passado. Ao fim e ao cabo, Hegel já notara, ambos são construções e aceitar essa condição é o primeiro passo para nos libertarmos de um hegelianismo tacanho, aquele mesmo que esquece daquilo que Foucault outrora notou: sempre tentamos nos libertar dele, Hegel sempre nos espera ao fim, por mais que dele tentemos fugir. Assim, talvez o caminho para não sermos tão hegelianos - a esperança de Foucault para o século ${ }^{16}$ - seja justo sermos hegelianos, uma vez que é um destino inescapável, malgrado a belíssima tentativa de Lebrun e de outros filósofos do século XX e XXI de pôr a dialética do avesso a partir de Nietzsche. Quando descobrimos que

15 LACAN, 1986, p.9.

16 FOUCAULT, 1972, p.235. 
a questão hegeliana não é tanto epistemológica ou conteudística quanto também e lógica e ontológica - e, portanto, muitíssimo enraizada na linguagem e nos usos que dela fazemos - descobrimo-nos em toda parte cercados de hegelianismo, pensado ou não. Resta agora saber se existe um “fora” disso.

\section{REFERÊNCIAS}

BECKETT, S. The unnamable. London: Faber and Faber, 2010.

EAGleton, T. A ideologia da estética. Trad. Mauro Sá Rego Costa. Rio de Janeiro, RJ: Jorge Zahar, 1993 .

FOUCAULT, M. Discourse on knowledge. in: The Archaeology of knowledge. Nova York: Pantheon, 1972.

HEGEL, G. Fenomenologia do Espírito I. Trad. Paulo Menezes. Petrópolis, RJ: Vozes, 1992. Lições sobre a filosofia da História. $2^{\mathrm{a}}$ edição. Trad. Maria Rodrigues e Harden. Brasília: Editora da UnB, 1999.

. Grundlinien der Philosophie des Rechts [online]. Disponível: http://www. cosmopolitanuniversity.ac/library/Hegel.Grundlinien.der.Philosophie.des.Rechts.pdf. Acesso em 05/09/2017.

LACAN, J. O seminário: Os escritos técnicos de Freud. Rio de Janeiro: Jorge Zahar, 1986. LEBRUN. G. O avesso da dialética: Hegel à luz de Nietzsche. Trad. Renato Janine Ribeiro. São Paulo, SP: Companhia das letras, 1988.

RAUCH, L. Translator's introduction in: HEGEL, G.W.F. Introduction to the Philosophy of History. Indianapolis: Indiana, HPC, 1988b.

SAFATLE, V. O circuito dos afetos. São Paulo, SP: Cosac Naify, 2015. 